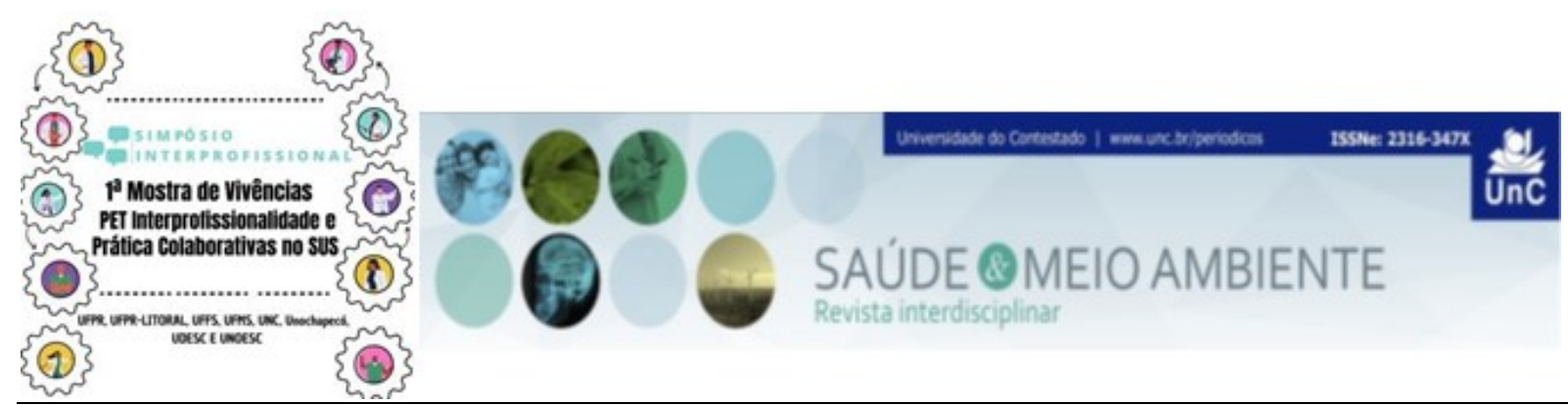

\title{
ASPECTOS FíSICOS E MENTAIS DA QUALIDADE DE VIDA DE PROFISSIONAIS DA EDUCAÇÃO BÁSICA DO MUNICÍPIO DE PARANAGUÁ-PR ${ }^{1}$
}

\author{
Projeto 93 Pet-Saúde Interprofissionalidade \\ Lígia Panhozi de Camargo Nogueira ${ }^{2}$ \\ Tainá Ribas Mélo ${ }^{3}$ \\ Roberto Eduardo Bueno ${ }^{4}$ \\ Silmara Souza Lima ${ }^{5}$ \\ Vanessa de Oliveira Lucchesi ${ }^{6}$ \\ Evaldo Ribeiro Junior ${ }^{7}$
}

\begin{abstract}
RESUMO
Introdução: A Qualidade de Vida (QV) está relacionada aos fatores que influenciam o dia-a-dia dos indivíduos, referindo-se à satisfação física, psicológica e social, bem como, à percepção do indivíduo em relação a sua posição na vida, contexto cultural e sistema de valores e expectativas que permita uma visão ampliada sobre a condição de saúde. ${ }^{1}$ Conforme o levantamento realizado nos departamentos de Recursos Humanos, Saúde ocupacional, Ouvidoria da Secretaria Municipal de Educação e Ensino Integral (SEMEDI) e Escolas da rede municipal, foi identificado um aumento do indicativo de afastamentos de servidores com auxílio-doença, restrições e readaptações. $^{2} \mathrm{Na}$ perspectiva da promoção e prevenção à saúde, criou-se o "Programa de Atenção à Saúde e Valorização do Professor" voltadas para a saúde mental e física, com o apoio de Psiquiatra, Psicopedagoga, Psicóloga e Yoga, com parceria do Projeto PET Saúde da UFPR Litoral, de maneira a favorecer a atenção integral à saúde com articulação interprofissional e intersetorial. Objetivo: Analisar a QV de Profissionais da rede pública de ensino básico do município de Paranaguá PR. Método: Estudo de natureza descritivo quantitativo com aprovação do Comitê de Ética e Pesquisa do parecer $n^{\circ}$ 2.884.824. De maneira a atender uma avaliação dos

${ }^{1}$ Fonte de financiamento: Programa de Educação pelo Trabalho para a Saúde - PET

Saúde/Interprofissionalidade 2019-2021 (Edital no 10 de 23 de julho de 2018, Ministério da

Saúde/Secretaria de Gestão do Trabalho e da Educação na Saúde).

${ }^{2}$ Bolsista do PET - Acadêmica do curso de Serviço Social. Universidade Federal do Paraná - Setor

Litoral. Paraná. Brasil. E-mail: ligiapanhozi@gmail.com

${ }^{3}$ Tutor do PET. Docente do curso de Saúde Coletiva. Universidade Federal do Paraná - Setor Litoral.

Paraná. Brasil. E-mail: ribasmelo@gmail.com

${ }^{4}$ Tutor no PET. Docente do curso de Saúde Coletiva. Universidade Federal do Paraná - Setor Litoral.

Paraná. Brasil. E-mail: roberto.edu.bueno@gmail.com

${ }^{5}$ Preceptora do PET- Psicóloga da Prefeitura Municipal de Paranaguá. Paraná. Brasil. E-mail:

sil9@uol.com.br

${ }^{6}$ Preceptora do PET - Fonoaudióloga da Prefeitura Municipal de Paranaguá. Paraná. Brasil. E-mail: lucchesi_fono@yahoo.com.br

${ }^{7}$ Tutor/Coordenador de equipe PET - Universidade Federal do Paraná - Setor Litoral. Paraná. Brasil. E-mail: evaldoribeirojr@gmail.com
\end{abstract}


componentes físicos (CF) e mentais (CM), utilizou-se o instrumento Short Form Survey (SF-12) na análise de 99 profissionais da rede municipal de Paranaguá, que responderam ao questionário. O SF-12 avalia o CF e CM para oito dimensões da QV nas últimas quatro semanas: função física, aspecto físico, dor, saúde geral, vitalidade, função social, aspecto emocional e saúde mental, além de possuir rápida e fácil aplicação. A pontuação varia em uma escala de zero a 100, os maiores escores associados a melhores níveis de QV, sendo no Brasil considerado satisfatório um escore, em média, maior que $50 .{ }^{3}$ Resultados: As profissionais avaliadas, com idade entre 19 e 60 anos (42 \pm 9 ), apresentaram as seguintes profissões de: Assessora (1), Educadora (43\%), Pedagoga (7\%) e Professora (47\%), escolaridade sendo maioria graduação (47\%) e 29 \% com pós-graduação e as demais com superior incompleto e ensino médio completo/incompleto. Em relação a QV, por meio do SF-12, apresentam escores médios insatisfatórios para $\mathrm{CF}=44,12$ e $\mathrm{CM}=42,04$, com escores inferiores a 50 para $62 \%$ no $\mathrm{CF}$ e $73 \%$ no $\mathrm{CM}$ da amostra. Conclusão: Observa-se impacto na QV das profissionais avaliadas, tanto no componente físico, como mental, ratificando a necessidade de programas voltados à atenção de suas condições de saúde e de $\mathrm{QV}$, de maneira a promover e estimular, por meio de um trabalho interprofissional, a adoção estilo de vida saudável e por consequência melhores condições de saúde para o trabalho. Observa-se a importância de um aprofundamento na investigação, a fim de compreender os fatores que influenciam nessa baixa percepção de QV considerando a integralidade da atenção em saúde.

Palavras-chave: Qualidade de Vida. Ensino Fundamental e Médio. Docentes.

\section{REFERÊNCIAS}

1. Fleck MPA, organizador. A avaliação de qualidade de vida: guia para profissionais da saúde. Porto Alegre: Artmed, 2008.

2. Redação Agora Litoral. Educação de Paranaguá recebe prêmio pelo Programa Saúde do Professor. [Acesso 16 de Março de 2020]. Disponível em: https://agoralitoral.com.br/noticias/educacao-de-paranagua-recebe-premio-peloprograma-saude-do-professor/

3. Silveira MF, Almeida JC, Freire RS, Haikal DAS, Martins AEBL. Propriedades Psicométricas do instrumento de avaliação de qualidade de vida: 12-item health survey (SF-12). Rev. Cien Saude Colet., 2013; 18(7):1923-31. 